\title{
Sorafenib: is a partial response and stabilization of disease greater than $70 \%$ a modest response?
}

\section{Dear Editor}

I read with great interest the recently published Metaanalysis on sorafenib use in patients with radioiodine refractory thyroid cancer (Shen et al. 2014). In this study, seven investigations were analyzed and pooled results showed that more than $70 \%$ of patients achieved a partial response (PR) or stabilization of disease (SD), with a median progression-free survival of 1 year. Also, the authors showed than around $80 \%$ of patients presented side effects when all grades of adverse events (AE) were considered. The authors concluded that sorafenib showed only a modest effect in patients with advanced thyroid cancer. I wonder if $70 \%$ of PR plus SD would be considered as a modest response to treatment of patients with advanced progressive disease with few other therapeutic options available at this moment. Perhaps the authors considered that only $22 \%$ of patients had a PR, without taking into account the SD, which is more difficult to attribute to a direct effect of sorafenib treatment and this allowed them to conclude that it was a modest response. What we should consider is that despite the significant revisions made in RECIST 1.1, numerous issues remain to be resolved in the assessment of tumor responses in clinical practice. Subcentimeter-sized lesions are considered to be non-measurable by RECIST 1.1 criteria, resulting in difficulties in the quantization of the tumor burden and response. Furthermore, treatment with tyrosine kinase inhibitors (TKI) may result in cavitation of lesions, with internal necrosis without a change in lesion size, which is a challenge for radiologists who aim to obtain the measurement that best represents the tumor burden. Thyroglobulin measurements, in concordance with RECIST 1.1, could be an additional valuable tool in the evaluation of tumor responses (Ruan et al. 2013).

On the other hand, treating patients with advanced radioiodine-refractory thyroid cancer with classical options such as doxorubicin generally produces disappointing response rates and usually more significant toxicity than that reported for sorafenib (Shimaoka et al. 1985, Argiris et al. 2008, Matuszczyk et al. 2008).

It is clear that a great proportion of patients will present AEs related to sorafenib treatment. In around $30-80 \%$ of these analyzed series (Shen et al. 2014), patients presented any AEs that were mostly grade 1 or 2 . The majority of these side effects can be managed in centers with experienced staff, and patients can continue their treatment with several options that may include a short withdrawal or a dose reduction (Cabanillas et al. 2011).

I found the whole meta-analysis very interesting, but I think that the final conclusions are not related to the main findings of the investigation, considering that we are not referring to those patients with 'only' thyroid cancer, but to a subset of patients with a progressive advanced disease who usually have a poor overall prognosis, with 10-year survival rates of only $10 \%$, and death occurring frequently within 3 years after progressive radioiodine resistance is diagnosed (Durante et al. 2006, Pfister \& Fagin 2008). Overall survival may be the best evaluation index for the treatment response in radioiodine-refractory differentiated thyroid cancer (DTC) patients. Unfortunately, no data that compares the differences between any TKI arm and placebo or other agents arm has been reported in advanced thyroid cancer. Finally, in these patients who have no other option of treatment at this moment, the increase in PFS and probably, the overall survival, to my opinion will not make this a modest result.

Fabián Pitoia

Division of Endocrinology, Hospital de Clínicas, University of Buenos Aires, Buenos Aires, Argentina

(Correspondence should be addressed to F Pitoia); email: fpitoia@intramed.net

Published by Bioscientifica Ltd 


\section{Declaration of interest}

I declare that there is no conflict of interest that could be perceived as prejudicing the impartiality of the research reported.

\section{Funding}

This research did not receive any specific grant from any funding agency in the public, commercial or not-for-profit sector.

\section{References}

Argiris A, Agarwala SS, Karamouzis MV, Burmeister LA \& Carty SE 2008 A phase II trial of doxorubicin and interferon $\alpha 2 \mathrm{~b}$ in advanced, non-medullary thyroid cancer. Investigational New Drugs 26 183-188. (doi:10.1007/s10637-007-9091-2)

Cabanillas ME, Hu MI, Durand JB \& Busaidy NL 2011 Challenges associated with tyrosine kinase inhibitor therapy for metastatic thyroid cancer. Journal of Thyroid Research 2011 985780. (doi:10.4061/2011/985780)

Durante C, Haddy N, Baudin E, Leboulleux S, Hartl D, Travagli JP, Caillou B, Ricard M, Lumbroso JD \& De Vathaire F 2006 Long-term outcome of 444 patients with distant metastases from papillary and follicular thyroid carcinoma: benefits and limits of radioiodine therapy. Journal of Clinical Endocrinology and Metabolism 91 2892-2899. (doi:10.1210/ jc.2005-2838)

Matuszczyk A, Petersenn S, Bockisch A, Gorges R, Sheu SY, Veit P \& Mann K 2008 Chemotherapy with doxorubicin in progressive medullary and thyroid carcinoma of the follicular epithelium. Hormone and Metabolic Research 40 210-213. (doi:10.1055/s-2008-1046781)

Pfister DG \& Fagin JA 2008 Refractory thyroid cancer: a paradigm shift in treatment is not far off. Journal of Clinical Oncology 26 4701-4704. (doi:10.1200/JCO.2008.17.3682)

Ruan M, Shen Y, Chen L \& Li M 2013 RECIST1 and serum thyroglobulin measurements in the evaluation of responses to sorafenib in patients with radioactive iodine-refractory differentiated thyroid carcinoma. Oncology Letters 6 480-486. (doi:10.3892/ol.2013.1424)

Shen CT, Qiu Z \& Luo QY 2014 Sorafenib in radioiodine-refractory differentiated thyroid cancer: a meta-analysis. Endocrine-Related Cancer 21 253-261. (doi:10.1530/ERC-13-0438)

Shimaoka K, Schoenfeld DA, DeWys WD, Creech RH \& DeConti R 1985 A randomized trial of doxorubicin versus doxorubicin plus cisplatin in patients with advanced thyroid carcinoma. Cancer 56 2155-2160. (doi:10.1002/1097-0142(19851101)56:9<2155::AIDCNCR2820560903 > 3.0.CO;2-E)

Received in final form 16 January 2014

Accepted 24 January 2014

Made available online as an Accepted Preprint

24 January 2014
(C) 2014 Society for Endocrinology Printed in Great Britain
Published by Bioscientifica Ltd. 